\title{
CLOSED OR OPEN INTRAMEDULLARY NAILING OF FEMORAL SHAFT FRACTURES?
}

\author{
A Comparison with Conservatively Treated Cases
}

\author{
P. Rokkanen, P. Slätis and E. Vankka, Helsinki, Finland \\ From the Clinic for Orthopaedics and Traumatology, University of Helsinki
}

Intramedullary nailing of femoral shaft fractures, first introduced by Hey Groves in 1918 and later popularised by Küntscher (1940, 1958, 1967), Böhler (1951), Street (1951) and Lottes (1953), is in most current textbooks described as a routine surgical operation. It is regarded as the method of choice in transverse and short oblique fractures of the femoral shaft (Böhler 1951; Müller, Allgöwer and Willenegger 1965) where good to excellent results have been reported. Nichols (1963), reviewing the results of rehabilitation after femoral shaft fractures. also reported better end-results after intramedullary nailing than after any other method of treatment.

Perusal of the literature reveals, however, some dissatisfaction with the method. The technical performance of the operation is far from uniform, and obviously it often falls far short of the standard demanded by Küntscher (Rehm and Uebing 1963). Chronic osteitis, delayed union and non-union are sequelae frequently reported after intramedullary nailing (Lauritzen 1949, Palmer 1951, Charnley and Guindy 1961, O’Brien 1963). Dencker (1965), reviewing the results of different methods of treatment of femoral shaft fractures in Swedish hospitals from 1952 to 1954 , concluded that although many of the nailed fractures did quite well, the rate of complications was so high that conservative treatment with traction should still be given preference in routine work in surgical wards.

Recent refinements in surgical techniques have materially altered intramedullary nailing. The introduction of the strong clover-leafed nail combined with the principle of reaming out the medullary canal (Küntscher 1958, 1959) and the development of image intensifiers have revived interest in closed nailing. Both Küntscher (1959) and Böhler (1965) reported encouraging results with such a technique. However, the evaluation of closed nailing as a routine procedure has not been possible for lack of comparative studies on selected series treated by other methods.

In this report an attempt is made to assess the value of primary closed intramedullary nailing of femoral shaft fractures, as compared with ordinary open intramedullary nailing and with conservative treatment.

\section{MATERIAL}

The series comprises 154 patients with 156 fractures of the femoral shaft treated at the Clinic for Orthopaedics and Traumatology, University of Helsinki, during a three and a half year period (March 1, 1963, to August 30,1966). Out of the entire series, 118 fractures were treated by intramedullary nailing. In fifty-four of these the nailing was done by a closed technique without exposing the fracture site, and using an image intensifier. In sixty-four fractures the traditional retrograde nailing technique with open reduction of the fracture was used (Street 1951).

There remained thirty-eight conservatively treated femoral shaft fractures. This control group was selected out of the conservatively treated femoral fracture series of the Clinic during the corresponding period, and included only fractures which, on account of location and type. would have been technically suitable for intramedullary nailing. 
Age-The age of the patients ranged from fourteen to eighty years. The mean of the patients treated by closed and open nailing was thirty-six years and thirty-four years respectively. In the conservatively treated group, as well as in the total series, the mean age was thirty-five years. Nine patients were under sixteen years old, fifty-five were aged sixteen to twenty-four, seventy-seven were aged twenty-five to sixty-four and thirteen were over sixty-five years old. There were more men than women in the series, the ratio being $2 \cdot 4: 1$.

Mechanism of injury-Traffic accidents were the cause in 78 per cent, industrial accidents in 12 per cent and domestic accidents in 10 per cent. The severity of the fracture in the different treatment groups is shown in Table I. The three groups were roughly comparable in respect

TABLE I

Severity of the Fractures in the Different Treatment Groups*

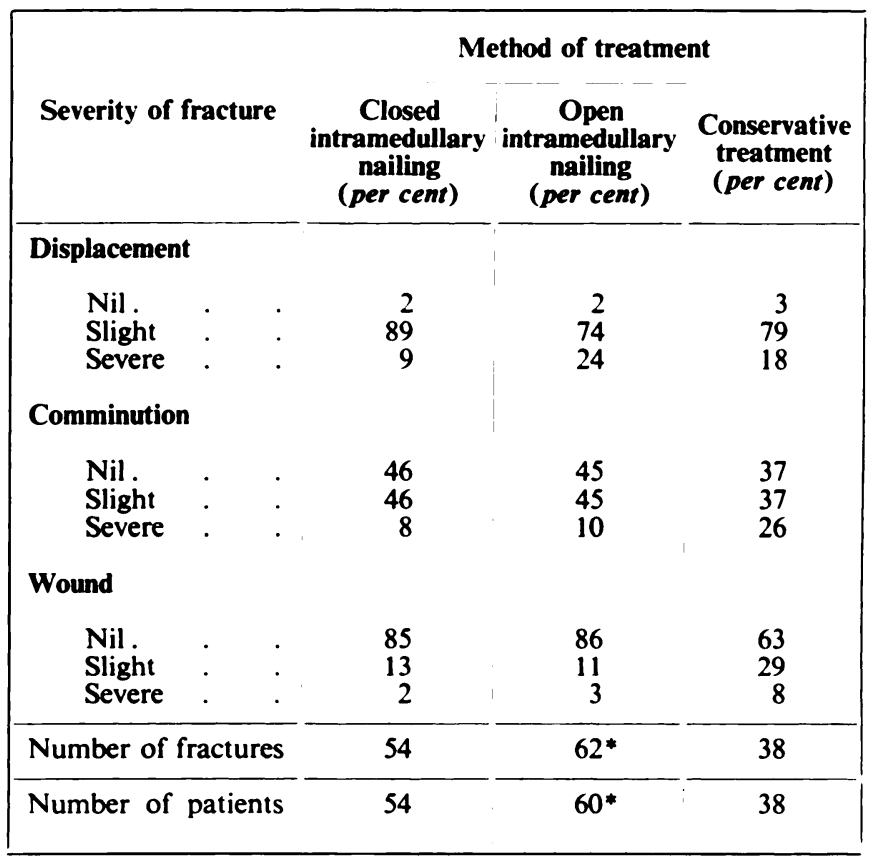

* Two deaths excluded.

of degree of displacement, comminution and occurrence of complicating wounds. In the conservatively treated group, however, there was a slight preponderance of severe comminution. Compound fractures accounted for 21 per cent of the entire series.

Site of fracture-In 79 per cent the fracture was located in the middle third of the femoral shaft, in 13 per cent in the uppermost third and in 8 per cent in the lowest third.

Severe injuries to other parts of the body were recorded in 57 per cent of the patients treated by closed nailing, in 52 per cent of those treated by open nailing and in 36 per cent of the conservatively treated cases.

\section{METHODS}

Closed intramedullary nailing-This was done under general anaesthesia with the patient in the lateral position on a fracture table (Fig. 1), using the following technique. Before skin cleansing and draping, the fracture is reduced with the aid of the image intensifier, the reduction manoeuvre being repeated by the assistant until he can easily maintain an appropriate reduction. Almost perfect alignment of the fragments is the key to successful closed intramedullary 
nailing, the part played by the assistant during the introduction of the instruments being of the utmost importance. The patient is carefully draped, leaving only a narrow area exposed in the trochanteric region (Fig. 2).

Through a muscle-splitting incision five to eight centimetres in length the medullary canal is entered along the medial surface of the greater trochanter. A guide wire is manipulated

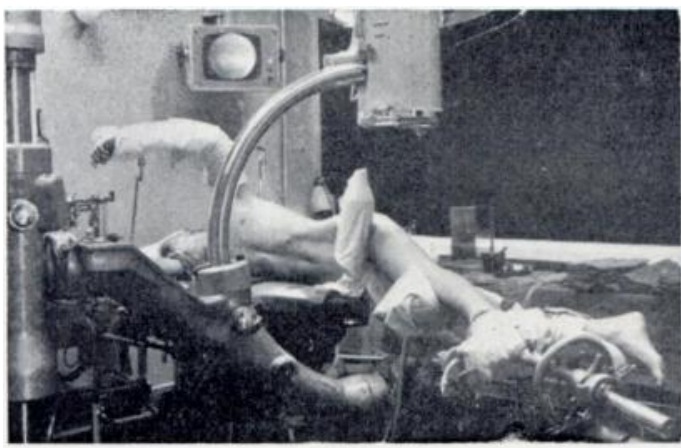

FiG. 1

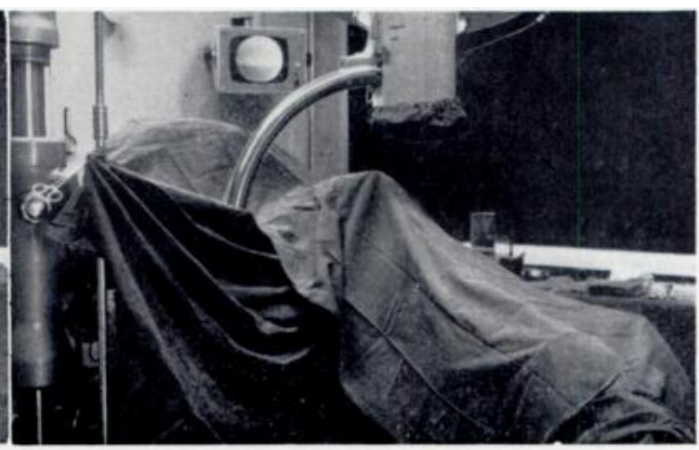

Fig. 2

Closed intramedullary nailing of femoral shaft fractures. The anaesthetised patient is placed in the lateral position on a fracture table (Fig. 1). Reduction of the fracture is achieved with the aid of an image intensifier mounted on a $\mathrm{C}$-arch, allowing control in two planes. The operation area is draped, leaving only a narrow bare area at the tip of the trochanter (Fig. 2). The introduction of the guide wire, the intramedullary reamers and the nail is conducted without exposing the fracture site and with the aid of the image intensifier.

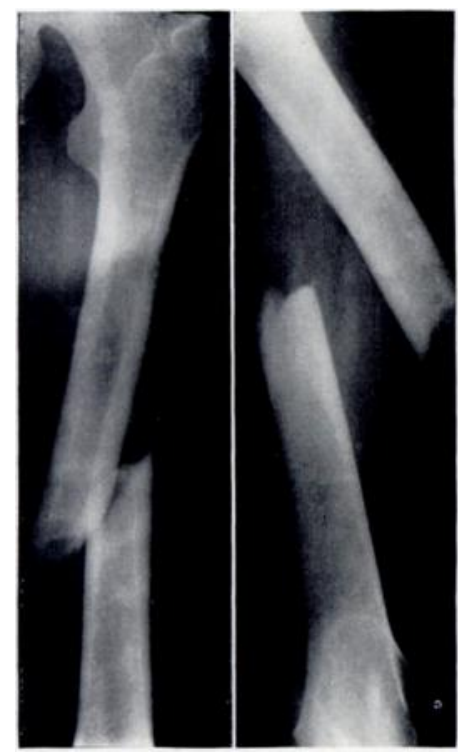

Fig. 3

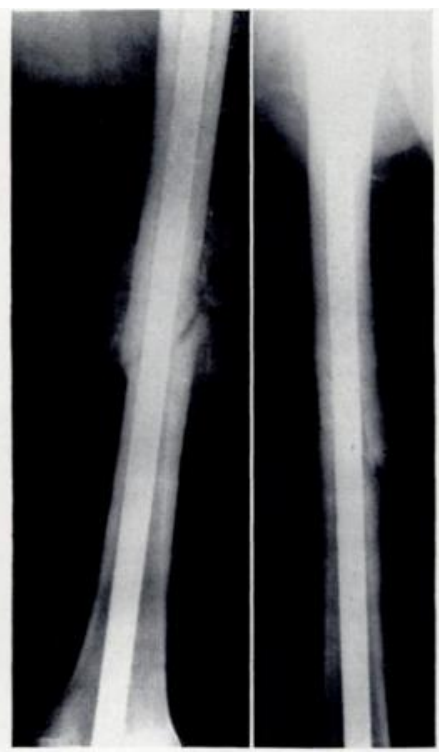

FiG. 4

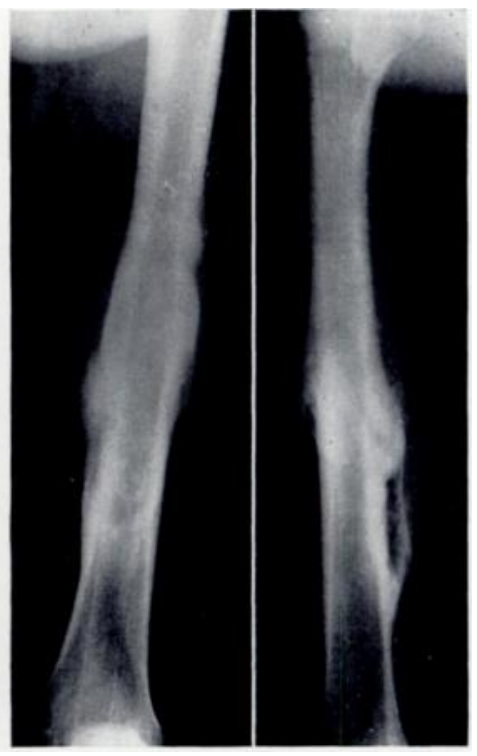

Fig. 5

A 25-year-old man sustained a compound, severely displaced fracture of the femoral shaft in a traffic accident (Fig. 3). Closed intramedullary nailing was done on the sixth day after the fracture. Six weeks later callus had developed around the fracture (Fig. 4). Walking without a stick was recorded twenty weeks after the operation and the patient returned to work as a mechanic twenty-four weeks after the accident. The radiograph in Figure 5 shows the result eighteen months after the operation. The nail has been removed.

through the medullary canal across the fracture into the distal fragment right down to the level of the base of the patella. Along the guide wire flexible reamers are introduced into the medullary canal, which is enlarged successively up to a diameter of 11-16 millimetres. The diameter of the clover-leafed nail should be 0.5 millimetre less than the inner diameter of the medullary canal. The distance from the tip of the greater trochanter to the upper margin of the patella is measured, and a nail of appropriate length and width is introduced along the

VOL. $51 \mathrm{~B}$, NO. 2, MAY 1969 
guide wire into the medullary canal. The nail is tapped down the line and should enter the cavity without difficulty, advancing readily with every blow of the hammer. The position of the fracture site and of all instruments introduced into the medullary canal should frequently be checked in two planes with the image intensifier. After the nail has been driven home, plain radiographs are taken of the entire femur, including both the fracture site and both ends of the nail. The wound is closed in layers and the patient lifted into bed with the leg elevated on pillows (Figs 3 to 5).

Open intramedullary nailing-Open nailing was done by the retrograde technique (Street 1951). The average size of the nails used in this series was 12 millimetres.

Post-operative care-After closed or open intramedullary nailing the patients were allowed to move freely in bed and a few days later were encouraged to walk with crutches. Leg elevation and knee exercises were started during the first week after operation. Partial weight-bearing was allowed in suitable transverse fractures within a few weeks after the operation, but full weight-bearing was not permitted until the radiographs showed that callus formation was well advanced. The average time for full weight-bearing was twelve weeks after closed nailing and fifteen weeks after open nailing.

In all but one case closed intramedullary nailing was done within three weeks after the injury, the mean interval between accident and nailing being seven days. Usually closed fractures were operated upon early, whereas in open fractures the operation was postponed until the wound had healed. In two patients with extensive soft-tissue injuries and denuded bone fragments the operation was done on the day of the accident after appropriate resuscitation.

In fifty-six out of sixty-four fractures open intramedullary nailing was performed within three weeks, but in the other eight cases the operation had to be postponed on account of severe concomitant injuries to other parts of the body. The mean time between the accident and the operation in this group was ten days.

Conservative treatment-When conservative treatment was employed the fracture was reduced and retained by balanced traction on a Böhler frame. In several patients traction was supplemented by a plaster hip spica. The time of immobilisation in the conservatively treated group ranged from five to twenty-seven weeks (mean eighteen weeks).

Follow-up-All patients were followed up until the end of treatment. In addition, all patients were summoned to a follow-up examination one to four years after the accident (average 2.9 years). The end-results were obtained in 113 out of 152 cases ( 74 per cent).

\section{RESULTS}

In the nailed fractures the time to solid union could not be determined by ordinary clinical methods, because in all patients the fracture was rendered stable by the heavy intramedullary nail. Moreover, radiological assessment of fracture repair during the first months after the operation is difficult and inconclusive. Therefore, functional results had to be chosen as criteria for the progress of fracture healing-namely the time elapsing between the accident and ability to walk without a stick, and the interval between the accident and return to work.

In the patients treated conservatively union was assessed by thorough clinical examination of fracture stability supplemented by plain radiographs. The time to union was recorded as the time to the discontinuance of immobilisation.

The time elapsing between the accident and ability to walk without a stick is shown graphically in Figure 6. From this it emerges that six months after the injury the nailed fractures did better than those treated conservatively. Closed nailing seemed to yield better results than open nailing. The same trend persisted twelve months after the accident: by that time all patients treated by closed nailing walked without a stick, compared with 96 per cent of the patients treated by open nailing and 81 per cent of the patients treated conservatively. 


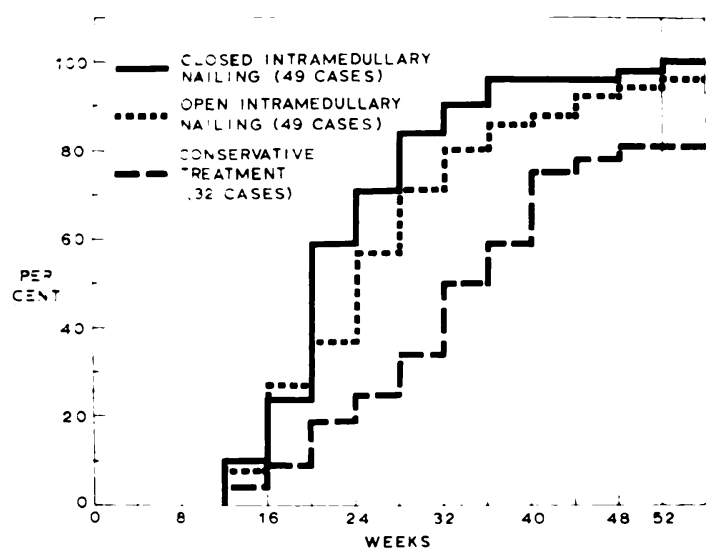

FIG. 6

The early functional result after femoral shaft fracture in three series treated either by closed intramedullary nailing, by open intramedullary nailing or by conservative measures. The ability to walk without a stick during the first year after the trauma is expressed in cumulative percentages.

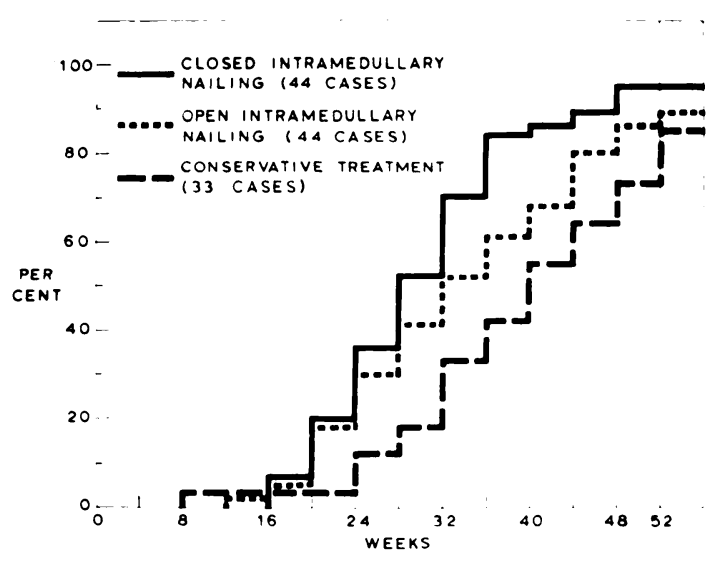

Fig. 7

The time interval between the accident and return to work after femoral shaft fracture in three series treated either by closed intramedullary nailing, by open intramedullary nailing or by conservative measures. Return to work is expressed in cumulative percentages.

Further analysis of these figures revealed that the benefit of closed intramedullary nailing varied according to the severity of the fracture and the age of the patient. The most gratifying results were obtained in patients over thirty-five years of age with severe fractures of the femur; these patients were able to walk without a stick on an average five months earlier than the corresponding group of patients treated conservatively (Table II). It should be noted, in contrast, that in young people the results of treatment were almost the same whether treatment was operative or conservative.

The interval between the accident and return to work in 121 patients is shown in Figure 7. In this respect, too, the patients treated by intramedullary nailing did better than those treated conservatively. Again, closed nailing appeared slightly superior to open nailing. Twelve months after the accident 95 per cent of those treated by closed nailing, 89 per cent of those treated by open nailing and 85 per cent of those treated conservatively had resumed work.*

The advantages of nailing were most evident in patients over thirty-five years of age with severe fractures, for these patients returned to work on an average three months earlier than the corresponding group of patients treated conservatively (Table III).

There was no appreciable difference in the results after early nailing (within one week after the accident) compared with those operated upon during the second and third weeks (Table IV). All fractures united within twelve months after the accident.

Duration of hospital treatment-In patients with only a femoral fracture the stay in hospital was shortest in the group treated by closed nailing. This group of patients stayed in hospital for an average of thirty-one days compared with thirty-five days for those treated by open nailing and seventy-one days for those treated conservatively.

\section{COMPLICATIONS AND FAILURES}

The complications and failures are summarised in Table V. Two patients died. One was a forty-year-old woman who died of pulmonary embolism on the ninth day after open nailing.

\footnotetext{
* Most patients were industrial workers, for whom accurate information could readily be obtained. The following thirty-one cases were omitted: eight schoolchildren, fifteen patients over sixty-five years of age or pensioned for other unrelated causes, three patients with another more severe injury restricting working capacity and five patients for whom no information could be obtained.
}

vol. $51 \mathrm{~B}$, NO. 2, MAY 1969 
TABLE II

Jnterval between Accident and Ability to Walk without a Stick

The table includes only fractures with severe displacement or comminution in patients of working age

\begin{tabular}{|c|c|c|c|}
\hline \multirow[t]{2}{*}{ Age groups } & \multicolumn{2}{|c|}{$\begin{array}{l}\text { Interval between accident and ability } \\
\text { to walk without a stick }\end{array}$} & \multirow{2}{*}{$\begin{array}{l}\text { Total number } \\
\text { of cases }\end{array}$} \\
\hline & Intramedullary nailing & Conservative treatment & \\
\hline Patients under 35 years of age & 26 weeks ( 15 cases) & 29 weeks ( 7 cases) & 22 \\
\hline Patients over 35 years of age & 33 weeks ( 9 cases) & 53 weeks ( 7 cases) & 16 \\
\hline
\end{tabular}

TABLE III

INTERVAL BETWEEN ACCIDENT AND RETURN TO WORK

The table includes only fractures with severe displacement or comminution in patients of working age

\begin{tabular}{|l|c|c|c|}
\hline \multicolumn{1}{|c|}{ Age groups } & \multicolumn{2}{c|}{ Interval between accident and return to work } & \multicolumn{1}{c|}{$\begin{array}{c}\text { Total number } \\
\text { of cases }\end{array}$} \\
\cline { 2 - 4 } & Intramedullary nailing & Conservative treatment & \\
\hline Patients under 35 years of age & 36 weeks (15 cases) & 37 weeks (7 cases) & 22 \\
Patients over 35 years of age & 43 weeks (9 cases) & 55 weeks (7 cases) & 16 \\
\hline
\end{tabular}

TABLE IV

Interval between Accident and Return to Work after Early and Delayed Nailing of Femoral Shaft Fractures

\begin{tabular}{|c|c|c|}
\hline Method of treatment & \multicolumn{2}{|c|}{ Interval between accident and return to work } \\
\cline { 2 - 3 } & $\begin{array}{c}\text { Nailing performed within } \\
\text { 6 days after the fracture }\end{array}$ & $\begin{array}{c}\text { Nailing performed } 7 \text { to } 21 \\
\text { days after the fracture }\end{array}$ \\
\hline Closed or open intramedullary nailing & 32 weeks (39 cases) & 30 weeks (49 cases) \\
\hline
\end{tabular}

TABLE V

Complications in 154 Cases with Fractures of the Femoral Shaft

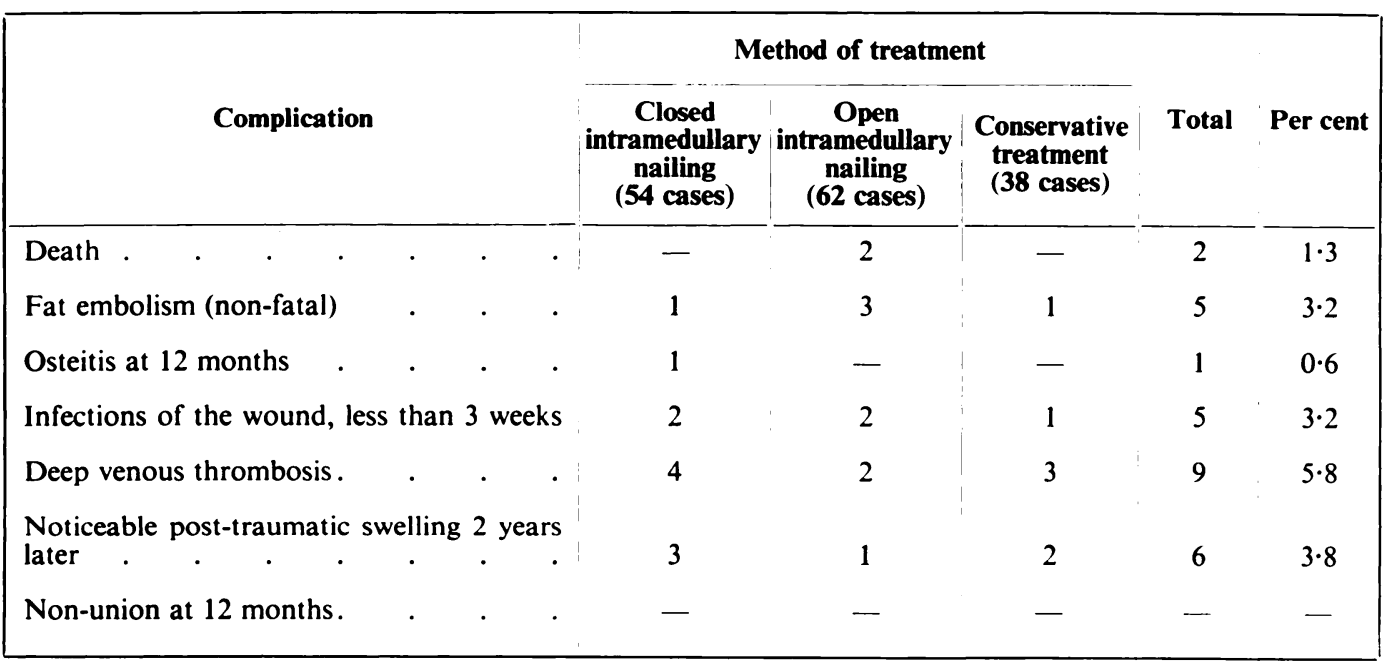


The other was an eighteen-year-old man who died from renal failure on the twenty-second day after open nailing and simultaneous repair of the femoral artery.

In one case osteitis occurred after closed intramedullary nailing and still continued, without a discharging sinus, as a low-grade infection at twelve months. The fracture eventually united, and the osteitis subsided and has not recurred. In four nailed patients and in one conservatively treated compound fracture, wound infection was recorded but it healed in all within three weeks and seemingly did not have any adverse effect on the fracture repair.

Deep venous thrombosis of the leg occurred in nine patients. At follow-up six patients complained of much swelling. In three, deep venous thrombosis had been observed earlier, and in one patient the swelling was caused by extensive constricting scars in the thigh from severe primary soft-tissue injury.

In five cases non-fatal fat embolism was observed clinically and verified by skin biopsy or radiographs of the chest. Fat embolism occurred on an average 2.4 days after the injury and invariably appeared before the intramedullary nailing.

No nail broke. One nail, 11 millimetres in diameter, bent as a result of a further injury and had to be changed.

The most frequent complaint in the nailed patients was slight discomfort in the trochanteric region at the tip of the nail. On enquiry, one patient in three was found to have

TABLE VI

Range of Knee Movement after Different Methods of

Treatment of Femoral Shaft Fractures

Follow-up examination of 113 patients

\begin{tabular}{|c|c|c|c|c|}
\hline \multicolumn{2}{|c|}{ Results of treatment } & \multirow{2}{*}{$\begin{array}{c}\begin{array}{c}\text { Closed } \\
\text { nailing } \\
\text { (per cent) }\end{array} \\
86\end{array}$} & \multirow{2}{*}{$\begin{array}{c}\begin{array}{c}\text { Open } \\
\text { nailing } \\
\text { (per cent) }\end{array} \\
79\end{array}$} & \multirow{2}{*}{$\begin{array}{c}\begin{array}{c}\text { Conservative } \\
\text { treatment } \\
\text { (per cent) }\end{array} \\
56\end{array}$} \\
\hline Good & . & & & \\
\hline Fair & . & 14 & 21 & 37 \\
\hline Poor & . & - & - & 7 \\
\hline \multicolumn{2}{|c|}{ Number of cases } & 42 & 43 & 28 \\
\hline
\end{tabular}

some pain in this area, which usually subsided after removal of the nail. There was no correlation between the subjective complaints and the degree of protrusion of the nail.

Residual deformity-At follow-up the degree of angular and rotational deformity was measured. In no fracture treated by closed nailing did the angular deformity exceed 10 degrees. Such deformity was, however, observed in 2 per cent of the fractures treated by open nailing and in 29 per cent of those treated conservatively.

Rotational deformity exceeding 10 degrees was recorded in 10 per cent of the fractures treated by closed nailing, in 11 per cent of the fractures treated by open nailing and in 4 per cent of the fractures treated conservatively.

Shortening of the limb by more than 2 centimetres was observed in 3 per cent of the fractures treated by closed nailing, in 4 per cent of those treated by open nailing and in 18 per cent of those treated conservatively.

Residual joint stiffness-At follow-up the range of movement at the hip, knee, ankle and tarsal joints was measured and compared with the intact side. The range of movement in the hip joint was equally good in all treatment groups. In the nailed patients discomfort at the site of the tip of the nail was common, but only in one case did a protruding nail prevent full range of movement at the hip.

VOL. 51 B, NO. 2, MAY 1969 
Residual stiffness of the knee was mainly encountered after fractures treated conservatively; the range of movement was definitely better after fractures treated by nailing (Table VI)*. A good range was thus obtained in 86 per cent after closed nailing, in 79 per cent after open nailing and in 56 per cent after conservative treatment. In no limb treated by nailing was the range of movement less than 90 degrees, whereas in the conservatively treated cases the range of movement was poor in 7 per cent.

There was no discernible difference in the range of movement at the ankle or tarsal joints between the different treatment groups.

\section{DISCUSSION}

Operative reduction and internal fixation of a fracture of a long bone invariably affects the vascularisation of the fracture area. The advantages of a stable reduction must therefore be weighed against the knowledge that an impaired blood supply after exposure of the fracture may result in deficient nutrition of the osteogenic cells and subsequent delayed union.

Experiments have shown (Göthman 1961, Trueta and Cavadias 1955, 1964) that the inner two-thirds of the cortex is nourished by branches from the medullary arteries, whereas the outer third of the cortex obtains its blood supply from the periosteal vessels. Severance of the medullary vessels does not result in nutritional changes in the cortex, because reactive activation of the periosteal vessels compensates for the severed medullary system (Göthman 1961).

In animals and in man fracture healing after intramedullary nailing is basically brought about by proliferation of the inner layer of the periosteum and subsequent formation of an ensheathing callus mass around the broken bone ends. The progress of healing thus largely resembles fracture repair during normal conditions (Slätis and Rokkanen 1965, 1967b). The more stable the fracture is rendered after nailing the less pronounced will be the periosteal reaction (Göthman 1961). Indeed, Küntscher (1964) claimed that if the fixation was rigid the process of repair was converted into direct bone formation between the fragments. This corresponds to the so-called primary callus observed after osteosynthesis with compression devices (Schenk and Willenegger 1964).

Thus, theoretically, closed intramedullary nailing is preferable to open intramedullary nailing, because by a closed technique the periosteal blood supply is preserved, and revascularisation of the fracture area can occur within a reasonable time. Further, if intramedullary nails of appropriate size are used, stable fixation can be achieved, which makes early mobilisation of the fractured limb possible.

It emerges from the present series that in femoral shaft fractures both the early and late results of treatment were better after intramedullary nailing than after conservative treatment. It is interesting that it was the difficult fractures in the older patients that benefited most from intramedullary nailing, whereas low-energy injuries in young people healed equally well regardless of the method of treatment.

It is obvious that the first reports of the results of intramedullary nailing of the femur should not be compared with recent reports. In the beginning unsuitable nails and faulty equipment caused numerous technical difficulties and led to failures amounting, in some series, to 14 per cent of the nailed cases (Dencker 1964). Modern flexible drills and a complete assortment of nails are imperative for successful intramedullary nailing. Few methods of osteosynthesis are so liable to technical failure from faulty equipment. Correspondingly, an appropriate set of instruments and a high quality image intensifier make closed intramedullary nailing of the femur an expedient surgical procedure. Metal fatigue and nail breakage should no longer complicate the late course of fracture healing, as is evident from the present series where, in 118 nailed fractures, only one nail bent.

* Grading of mobility at knee-Good = Full extension; loss of flexion less than 10 degrees. Fair = Any loss of extension; loss of flexion of 10 to 50 degrees. Poor=Loss of more than 10 degrees of extension; range of flexion-extension less than 90 degrees. 
Although the differences between results after open and closed nailing are not very great, we prefer closed nailing. It is less traumatic and hence better tolerated by the patient, and in most instances it is an easier surgical procedure than open reduction and nailing. If reduction proves difficult, however, owing to shortening or interposed tissue, forcible attempts at reduction should be avoided. In such cases time is saved and tissue damage reduced if the fracture is exposed and nailed by the open method.

In the whole series there was no non-union at twelve months after the fracture. Similar results have been reported by Böhler (1965). But several authors have reported a high incidence of delayed union, the figures varying from 4.3 per cent to 25 per cent (Palmer 1951. Charnley and Guindy 1961, O’Brien 1963, Dencker 1965, Wickstrom and Corban 1967). In our series there was no evidence to suggest that nailing delays union. Neither did nailing in any way promote union of the broken bone ends, as judged from the radiographs. In our opinion, the good results of intramedullary nailing of the femoral shaft are because of the good vascular conditions throughout the deep-seated bone, which favour abundant ingrowth of capillaries into the fracture area in a wide variety of pathological conditions created either by the fracture or by surgical intervention. Intramedullary nailing of a superficial bone, such as the tibia, has not given such good results (Slätis and Rokkanen 1967a).

Osteitis occurred in this series in one case. The infection eventually subsided without any recurrences during the four-year follow-up period. In another five cases wound infection was recorded. Thus the incidence of deep infection was 0.6 per cent and the overall rate of infection 3.8 per cent. These figures are lower than those reported recently by other authors, according to whom the rate of deep infection after intramedullary nailing ranges from 1 to 11 per cent (Böhler 1951, O'Brien 1963, Dencker 1965, Wickstrom et al. 1967).

Opinions diverge regarding the proper time for intramedullary nailing. Charnley and Guindy (1961) reported that in their experience delayed fixation of the fracture lowered the incidence of delayed union from 25 per cent to 7 per cent. Similarly, Smith (1964) reported an incidence of delayed union of only 0.8 per cent when the operation was postponed to the second week after the accident or later. Analysis of the present series, however, does not reveal any clear difference between early and delayed fixation of the fracture.

Which types of femoral shaft fractures should then be treated by intramedullary nailing? Most surgeons agree that the transverse and short oblique fractures are well suited for intramedullary nailing (Böhler and Böhler 1949; Böhler 1951; Küntscher 1965; Müller, Allgöwer and Willenegger 1965; Wickstrom et al. 1967). We agree with this, but in our opinion the closed technique of nailing allows a broadening of the indications for intramedullary osteosynthesis of femoral shaft fractures. In our experience, slight comminution of the fracture is no contra-indication to closed intramedullary nailing, provided that nails of an appropriate size are used. In fractures with severe comminution conservative treatment is usually resorted to, supplemented, if necessary, by bone grafting. However, in these cases too, recent experiences with closed intramedullary nailing have been encouraging. We have been forced to adopt rather broad indications by the fact that in our series over 70 per cent are traffic accident victims, with multiple injuries in two patients out of three. In these the plan of treatment as a whole may call for internal fixation of the femoral fracture: this is the case in severe brain injuries, multiple injuries to both lower extremities and in patients with simultaneous traumatic paraplegia, in which nursing problems are greatly reduced by internal fixation of the femoral fracture and avoidance of traction-suspension devices.

\section{SUMMARY}

1. A series of 154 patients with 156 femoral shaft fractures treated during a three and a half year period is reviewed. Fifty-four fractures were treated by closed intramedullary nailing, sixty-four by open intramedullary nailing and thirty-eight by conservative methods.

VOL. 51 B, NO. 2, MAY 1969 
2. All the patients had fresh fractures of a similar degree of severity. Seventy-eight per cent of the fractures were sustained in traffic accidents, and 21 per cent were compound.

3. The technique of closed intramedullary nailing is described in detail. The importance of a complete and faultless armamentarium and a high-quality image intensifier is emphasised.

4. All fractures united within twelve months after the accident.

5. The functional results were assessed upon the basis of walking ability and return to work. Nailed fractures did better than conservatively treated ones, and closed nailing was slightly superior to open nailing. At twelve months after the injury all patients treated by closed nailing walked without a stick, compared with 96 per cent of the cases treated by open nailing and 81 per cent of the conservatively treated patients. The same trend was noted regarding return to work.

6. The benefit of intramedullary nailing was partly dependent on the severity of the fracture and the age of the patient. The most gratifying results of nailing were obtained in patients over thirty-five years of age with severe fractures.

7. Osteitis occurred in one case treated by closed nailing, and low grade wound infections in five cases, representing an overall infection rate of 3.8 per cent.

8. Seventy-four per cent of the patients were examined one to four years after the fracture. There was less angular deformity and more rotational deformity in the nailed than in the conservatively treated fractures. The tip of the nail gave slight discomfort in the trochanteric area in one patient in three. Residual joint stiffness was infrequent in the nailed cases as compared to the conservatively treated ones.

9. The indications for closed intramedullary nailing of femoral shaft fractures are outlined.

We are much indebted to the former Head of this Clinic, Professor K. E. Kallio, under whose guidance the method of closed intramedullary nailing was adopted and developed.

\section{REFERENCES}

BöHLER, J. (1951): Results in Medullary Nailing of Ninety-five Fresh Fractures of the Femur. Journal of Bone and Joint Surgery, 33-A, 670.

BöHLER, J. (1965): Percutaneous Internal Fixation Utilizing the X-ray Image Amplifier. Journal of Trauma, $5,150$.

BöHlER, L., and BöHLER, J. (1949): Küntscher's Medullary Nailing. Journal of Bone and Joint Surgery, 31-A, 295.

Charnley, J., and Guindy, A. (1961): Delayed Operation in the Open Reduction of Fractures of Long Bones. Journal of Bone and Joint Surgery, 43-B, 664.

Dencker, H. (1964): Errors in Technique and Complications Specific to Intramedullary Nailing. A Study Based on 459 Nailed Femoral Shaft Fractures. Acta Orthopaedica Scandinavica, 35, 164.

Dencker, H. (1965): Shaft Fractures of the Femur: A Comparative Study of the Results of Various Methods of Treatment in 1,003 Cases. Acta Chirurgica Scandinavica, 130, 173.

GöthmaN, L. (1961): Vascular Reactions in Experimental Fractures. Microangiographic and Radioisotope Studies. Acta Chirurgica Scandinavica, Supplement 284.

Groves, E. W. Hey, (1918): Ununited Fractures, with Special Reference to Gunshot Injuries and the Use of Bone Grafting. British Journal of Surgery, 6, 203.

KünTSCHER, G. (1940): Die Marknagelung von Knochenbrüchen. Archiv für klinische Chirurgie, $200,443$.

Küntscher, G. B. G. (1958): The Küntscher Method of Intramedullary Fixation. Journal of Bone and Joint Surgery, 40-A, 17.

KüntSCher, G. (1959): Die Technik des Aufweitens der Markhöle. Chirurg, 30, 28.

KüntSCher, G. (1964): Primäre Knochenheilung. Langenbecks Archiv für klinische Chirurgie, 308, 452.

Küntscher, G. (1965): Intramedullary Surgical Technique and Its Place in Orthopaedic Surgery. My Present Concept. Journal of Bone and Joint Surgery, 47-A, 809.

KüntSCHER, G. (1967): Practice of Intramedullary Nailing. Springfield, Illinois: Charles C. Thomas.

Lauritzen, G. K. (1949): Medullary Nailing: a Clinical and Critical Study. Acta Chirurgica Scandinavica, Supplement 147.

Lotres, J. O. (1953): Complications and Errors in Technic in Medullary Nailing for Fractures of the Femur. Clinical Orthopaedics, 2, 38. 
Nichols, P. J. R. (1963): Rehabilitation after Fractures of the Shaft of the Femur. Journal of Bone and Joint Surgery, 45-B, 96.

O'Brien, J. P. (1963): Fractured Femoral Shafts. Australian and New Zealand Journal of Surgery, 33, 91.

Palmer, I. (1951): On the Complications and Technical Problems of Medullary Nailing. Acta Chirurgica Scandinavica, 101, 484.

Rehm, J., and UebiNG, D. (1963): Die Behandlung von Frakturen langer Röhrenknochen mit dem Marknagel nach Küntscher. Archiv für orthopädische und Unfall-Chirurgie, 55, 82.

SCHENK, R., and Willenegger, H. (1964): Zur Histologie der primären Knochenheilung. Langenbecks Archiv für klinische Chirurgie, 308, 440.

Slätis, P., and Rokkanen, P. (1965): The Normal Repair of Experimental Fractures. Acta Orthopaedica Scandinavica, 36, 221.

Slätis, P., and Rokkanen, P. (1967a): Closed Intramedullary Nailing of Tibial Shaft Fractures. Acta Orthopaedica Scandinavica, 38, 88.

Slätis, P., and Rokkanen, P. (1967b): The Mineral Phase in the Repair of Experimental Fractures. Annales Chirurgiae et Gynaecologiae Fenniae, 56, 193.

Sмrтн, J. E. M. (1964): The Results of Early and Delayed Internal Fixation of Fractures of the Shaft of the Femur. Journal of Bone and Joint Surgery, 46-B, 28.

Street, D. M. (1951): One Hundred Fractures of the Femur Treated by Means of the Diamond-shaped Medullary Nail. Journal of Bone and Joint Surgery, 33-A, 659.

Trueta, J., and Cavadias, A. X. (1955): Vascular Changes Caused by the Küntscher Type of Nailing. An Experimental Study in the Rabbit. Journal of Bone and Joint Surgery, 37-B, 492.

Trueta, J., and Cavadias, A. X. (1964): A Study of the Blood Supply of the Long Bones. Surgery, Gynecology and Obstetrics, 118, 485.

Wickstrom, J., and Corban, M. S. (1967): Intramedullary Fixation for Fractures of the Femoral Shaft. A Study of Complications in 298 Operations. Journal of Trauma, 7, 551.

Müller, M. E., Allgöwer, M., and Willenegger, H. (1965): Technique of Internal Fixation of Fractures. Berlin, Heidelberg, New York: Springer-Verlag.

VOL. 51 B, NO. 2, MAY 1969 